Vol. 12, No. 45, October, 2017, 1417-1426

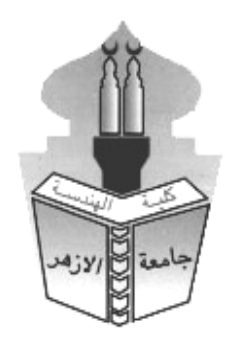

\title{
THE ROLE OF CEMENT CONTENT ON CONTROLLING THE COMPRESSIVE STRENGTH AND WATER ABSORPTION OF NANO SILICA CONCRETE
}

\author{
F.A. Megahed, I. A. Sharaky, A. A. M. Badawy, M. H. Seleem \\ Materials Engineering Dept., Faculty of Engineering, Zagazig University, Zagazig 44519, Egypt.
}

\begin{abstract}
This paper presents an experimental investigation on the effect of Nano Silica (NS) on the compressive strength of concrete made with different cement contents. Two percentages of NS, $1.5 \%$ and $3 \%$, as partial replacement of cement were investigated at cement contents of 300, 400, 500 and $600 \mathrm{~kg} / \mathrm{m}^{3}$. The effect of NS and cement contents on the compressive strength of concrete at different testing ages of 7,28 and 56 days was evaluated. The effect of NS and cement contents on the water absorption percentage (WA\%) was also investigated. The effect of cement content on the compressive strength ratios at 7 and 56 days to that at 28 days was found and correlated. The effects of cement content on the enhancement ratios of compressive strength and WA\% were also evaluated and correlated. NS addition enhanced the compressive strength and reduced the WA\%. The maximum enhancement in the compressive strength was recorded at $1.5 \% \mathrm{NS}$. As this ratio increased to $3 \%$, the compressive strength decreased but to a values not less than that of the concrete mix without NS.
\end{abstract}

\section{INTRODUCTION}

The Primary aim of materials science is to establish quantitive relationships between processing, structure and properties. For concrete, one of the most widely used technological materials, the processing- structure - property relationships are extremely complex. The development in concrete industry in recent years is devoted towards reducing the cement content by using supplementary cementitious materials (SCMs). The improvement in the concrete strength can be achieved by using SCMs such as silica fume or micro-silica, slag and fly ash.

However, the micro-level currently used does not provide enough visions into building materials. So, nanoscale gaining increasing attention. Nano silica (NS) seems to be the most popular nanoparticle in the researches [1]. Its high surface area to volume ratio providing the potential for chemical activity led to high rate of pozzolanic and filling the spaces between particles of gel of $\mathrm{C}-\mathrm{S}-\mathrm{H}$ thereby leading to reduced porosity [2]. In addition, it was found that NS promote the hydration reactions of $\mathrm{C}_{3} \mathrm{~S}$ due to the large and highly reactive surface of the nanoparticles [3]. In concrete, the behavior of materials in nanoscale rules the mechanical properties and the durability of it depend on improving of the paste-aggregate interface zone. The pozzolanic reaction of NS with calcium hydroxide increases the amount of $\mathrm{C}-\mathrm{S}-\mathrm{H}$, which improves the strength, and durability of the cement past and mortar [4]. It is more efficient in enhancing strength than SF [5]. The addition of NS up to $1.5 \%$ to the mixtures without additives increased the compressive strength to optimum. If the dosage of NS increased, the enhancement in strength decrease [6,7]. 
In concrete mixture containing superplasticizer with SF, the addition of $3 \%$ NS to mixtures results in a rise in compressive strength to optimum $[8,9]$.

Strength assessments and water permeability of concrete are joined together to affect the final performance of concrete. Nano particles can reduce the water absorption of concrete samples $[10,11]$. Jalal et al [12] found that the addition of $10 \%$ micro silica and $2 \%$ NS to concrete mixes showed a pronounced effect in reducing water absorption. Behfarnia and Salemi [13] studied samples of concrete containing 3\%, $5 \%$ and $7 \%$ NS by weight. They found that the percentage of water absorption of concrete containing nano-particles is remarkably lower than that of control sample.

The main objective of this research is to determine the properties of concrete incorporating SCMs in Nano-scale. The compressive strength of concrete containing NS at different cement contents and tested at 7,28 and 56 days was investigated. Water absorption (WA) of concrete containing NS at different cement contents and tested at 28 days was also investigated.

\section{THE EXPERIMENTAL PROGRAM}

As shown in Figure 1, the properties measured were compressive strength and water absorption tests at 7, 28 and 56 days. Four values of cement contents $\left(300,400,500\right.$ and $\left.600 \mathrm{~kg} / \mathrm{m}^{3}\right)$ were studied. Two percentages of NS $(1.5 \%$ and $3 \%)$ as partial replacement of cement were studied Superplasticizer was used for consistency adjustment. Trial mixes were made on the different investigated mixes to find the required quantity of superplasticizer needed for each mix to keep its slump value within the range of $80-100 \mathrm{~mm}$.

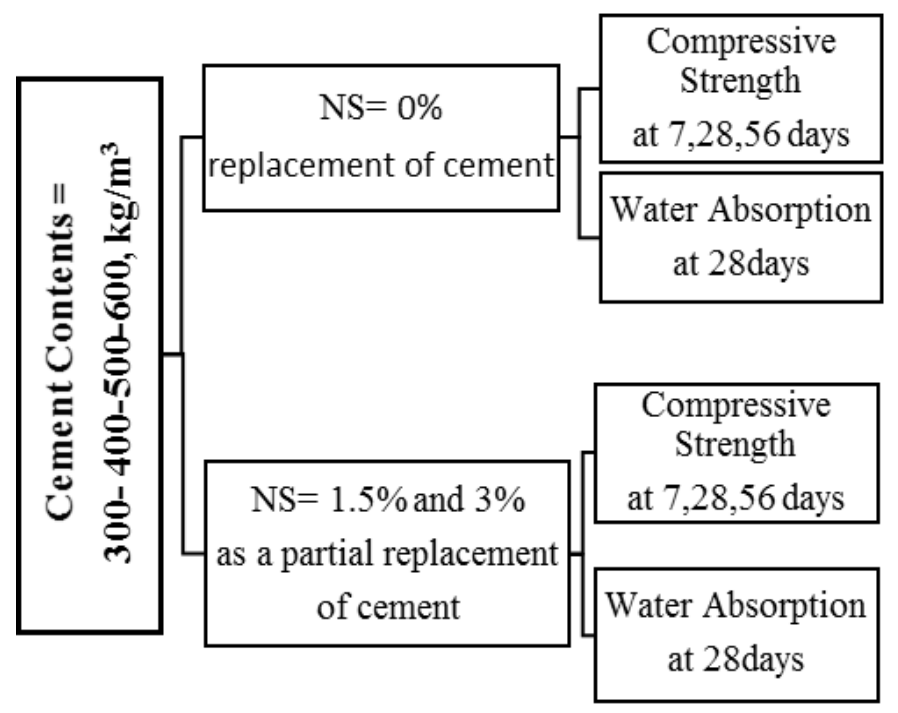

Figure 1: $\underline{\text { Layout }}$ of the experimental program

\subsection{Materials}

Concrete samples were prepared using Ordinary Portland Cement with grade CEM I $42.5 \mathrm{~N}$ complied with BS EN 197-1/2011 [14], and Egyptian Standard Specification ESS 47561/2013[15]. The used superplasticizer was Sikament-163, supplied by Sika Egypt for construction chemicals, complied with ASTM C-494 Type A\&F and BS 5075-3 with synthetic type dispersion base and density equal $1.2 \mathrm{~kg} /$ lit. Dosages of this highly effective water-reducing agent were changed in each samples to adjust slump value (80-100mm). Commercial Nano-SiO 2 (NS) in powder form was used. The physical properties and X-ray diffraction pattern of this type of NS is given in Table 1 and Figure 2 as obtained from the manufactures. NS was used as a partial replacement of cement by percentages of $1.5 \%$ and $3 \%$. Natural siliceous sand was used 
as fine aggregate. Local natural dolomite of $14 \mathrm{~mm}$ NMS from Ataka Mountain in Suez City was used as coarse aggregate. The physical properties and sieve analysis test results according to ESS 1109 for used fine and coarse aggregates are shown in Table 2 and Figure 3 respectively.

Table 1: Properties of used NS

\begin{tabular}{lc}
\hline Properties & Nano silica \\
\hline Appearance & Powder form \\
Colour & (White) \\
Particle size & $\approx 18 \mathrm{~nm}$ \\
Density $\left(25^{\circ} \mathrm{C}\right)$ & $2.2-2.6 \mathrm{~g} / \mathrm{mL}$ \\
Molecular & $\mathrm{SiO}_{2}$ \\
Purity & $89.0 \%$ \\
\hline
\end{tabular}

Table 2: Properties of used aggregates

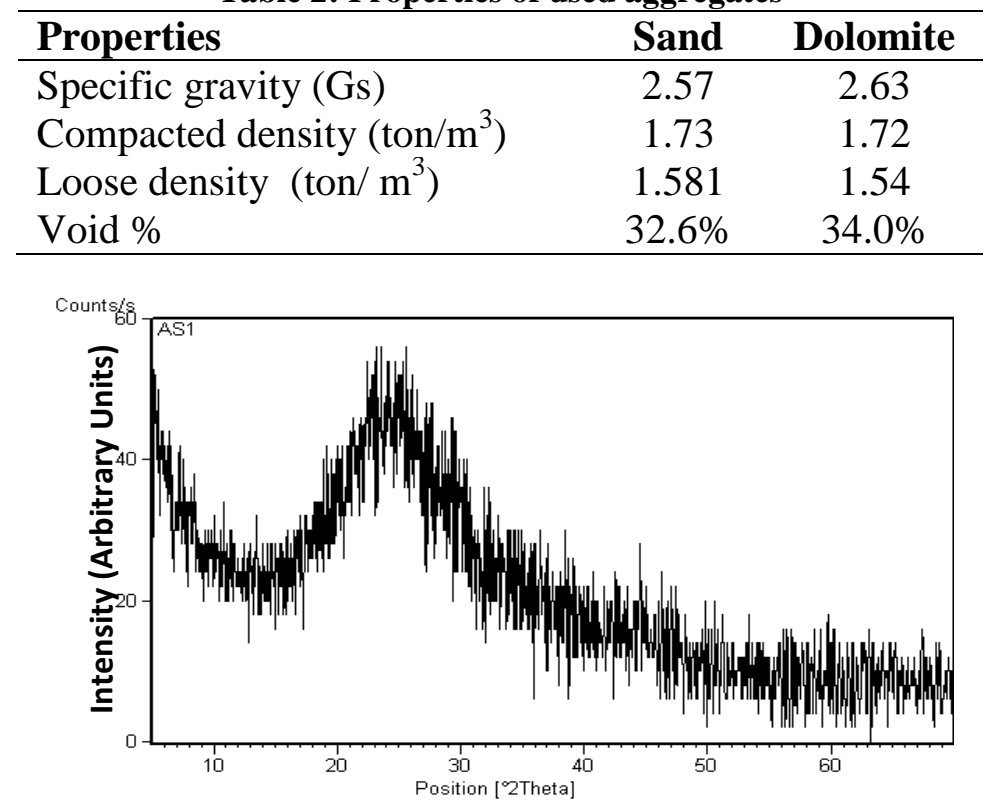

Figure 2: X-ray diffraction pattern of NS

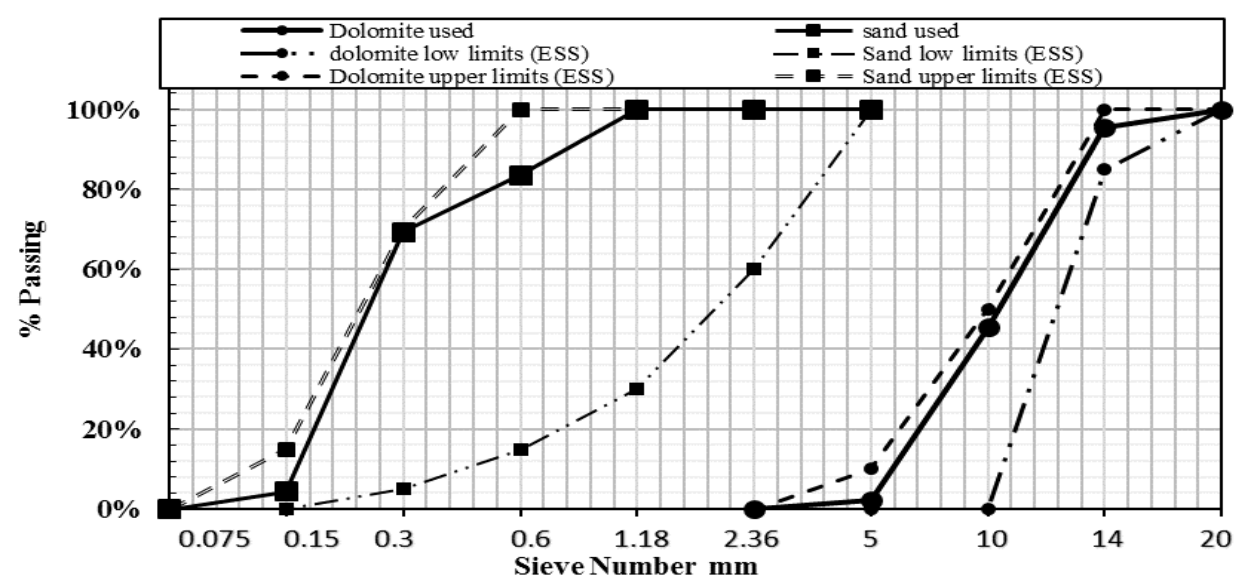

Figure 3: Grading curves of the used aggregates 


\subsection{Mix Design and Mixing Procedures}

All mixtures were designed by ACI method. The quantities of materials required to produce one cubic meter from each mix are given in Table 3. The legend of specimen refers to content of cement followed by nano percent $(\mathrm{N}-\%)$.

\begin{tabular}{|c|c|c|c|c|c|c|}
\hline \multirow[b]{2}{*}{ Symbol } & \multicolumn{5}{|c|}{ Quantity, kg/m ${ }^{3}$} & \multirow[b]{2}{*}{ SP } \\
\hline & $\begin{array}{l}\text { Cement } \\
\text { Content }\end{array}$ & Dolomite & Sand & $\begin{array}{l}\text { Water } \\
\text { Content }\end{array}$ & NS & \\
\hline $3 \mathrm{~N} 0.0$ & 300 & \multirow{12}{*}{1020} & 788 & \multirow{12}{*}{212} & & 0 \\
\hline $4 \mathrm{NO} 0.0$ & 400 & & 688 & & 0 & 0 \\
\hline $5 \mathrm{NO} 0.0$ & 500 & & 588 & & & 1.35 \\
\hline $6 \mathrm{~N} 0.0$ & 600 & & 488 & & & 1.36 \\
\hline $3 \mathrm{~N} 1.5$ & \multirow{2}{*}{300} & & \multirow{2}{*}{788} & & 4.5 & 0.25 \\
\hline $3 \mathrm{~N} 3.0$ & & & & & 9.0 & 0.25 \\
\hline $4 \mathrm{~N} 1.5$ & \multirow{2}{*}{400} & & \multirow{2}{*}{688} & & 6.0 & 0.75 \\
\hline $4 \mathrm{~N} 3.0$ & & & & & 12 & 1.28 \\
\hline $5 \mathrm{~N} 1.5$ & \multirow{2}{*}{500} & & \multirow{2}{*}{588} & & 7.5 & 2.40 \\
\hline $5 \mathrm{~N} 3.0$ & & & & & 15 & 2.66 \\
\hline $6 \mathrm{~N} 1.5$ & \multirow{2}{*}{600} & & \multirow{2}{*}{488} & & 9.0 & 2.20 \\
\hline $6 \mathrm{~N} 3.0$ & & & & & 18 & 2.60 \\
\hline
\end{tabular}

To prepare mixtures, laboratory drum mixer was used and the mixing procedures was as follows: mixing coarse aggregate, fine aggregate, cement and NS in dry form for 2 min. Then $50 \%$ of mixing water containing the whole amount of SP was combined, poured and mixed for 3 min. After that, about $1 \mathrm{~min}$ rest was allowed and finally the remaining water was added into the mixture and mixed for $1 \mathrm{~min}$. Before casting the mixture, the slump test was conducted according to BS 1881-102 [16]. It is clear that the measured slump values for all investigated mixes are within the range from $80-100 \mathrm{~mm}$ which confirmed with the slump range assumed in mixture design.

The fresh concrete was casted in cubes of $100 \mathrm{~mm}$ side length and stored at room temperature for the first $24 \mathrm{hrs}$. After being de-molded at the age of one day all specimens were removed, marked and cured in water at $20 \pm 1^{\circ} \mathrm{C}$ for 7,28 and 56 days. The hardened concrete samples were removed from curing tank at the specified testing age and any deposits on the specimens faces were removed before testing.

\subsection{Tests Procedures for Hardened Concrete}

Cube specimens $100 \mathrm{~mm}$ side length according to BS 1881-116 [17] were used to determine the compressive strength. Three specimens were cast for each mix to be tested at the specified ages of 7, 28 and 56 days of curing. Also, WA test was carried out at 28 days according to ASTM C 642-06 [18] by draying cube samples in oven at a temperature of 100 to $110^{\circ} \mathrm{C}$ for $24 \mathrm{~h}$ and then weighted $\left(\mathrm{W}_{1}\right)$. After that, the samples were submerged in water for $48 \mathrm{~h}$ followed by drying their surface and then weighted again $\left(\mathrm{W}_{2}\right)$. The WA\% was calculated as follows:

$$
\mathrm{WA} \%=\left(\mathrm{W}_{2}-\mathrm{W}_{1}\right) / \mathrm{W}_{1} * 100
$$

\section{RESULTS AND DISCUSSION}

The results of slump test, compressive strength $\left(f_{\text {cu }}\right)$ and water absorption (WA\%) for all investigated mixes are given in Table 4 
THE ROLE OF CEMENT CONTENT ON CONTROLLING THE COMPRESSIVE STRENGTH AND WATER ABSORPTION OF NANO SILICA CONCRETE

Table 4: compressive strength and water absorption results

\begin{tabular}{|c|c|c|c|c|c|c|c|}
\hline \multirow[t]{2}{*}{ Mixtures } & \multicolumn{2}{|l|}{$\mathrm{kg} / \mathrm{m}^{3}$} & \multirow{2}{*}{$\begin{array}{c}\text { Slump value, } \\
\mathbf{m m}\end{array}$} & \multicolumn{3}{|c|}{$f_{\text {cu, }}, \mathrm{MPa}$} & \multirow[t]{2}{*}{ WA, \% } \\
\hline & Cement content & NS & & 7 days & 28 days & 56 days & \\
\hline $3 \mathrm{~N} 0.0$ & \multirow{3}{*}{300} & 0 & 80 & 19.00 & 27.00 & 31.25 & 6.21 \\
\hline $3 \mathrm{~N} 1.5$ & & 4.5 & 80 & 27.00 & 31.00 & 33.00 & 5.15 \\
\hline $3 \mathrm{~N} 3.0$ & & 9.0 & 90 & 23.33 & 28.00 & 31.00 & 4.48 \\
\hline 4N0.0 & \multirow{3}{*}{400} & 0 & 90 & 27.33 & 34.67 & 38.00 & 4.67 \\
\hline $4 \mathrm{~N} 1.5$ & & 6.0 & 100 & 36.00 & 38.00 & 39.50 & 3.85 \\
\hline $4 \mathrm{~N} 3.0$ & & 12.0 & 100 & 34.00 & 36.00 & 38.00 & 3.34 \\
\hline $5 \mathrm{~N} 0.0$ & \multirow{3}{*}{500} & 0 & 90 & 39.00 & 46.00 & 53.00 & 3.57 \\
\hline $5 \mathrm{~N} 1.5$ & & 7.5 & 90 & 42.00 & 50.80 & 55.00 & 3.19 \\
\hline $5 \mathrm{~N} 3.0$ & & 15 & 100 & 40.00 & 48.00 & 54.00 & 3.02 \\
\hline $6 \mathrm{~N} 0.0$ & \multirow{3}{*}{600} & 0 & 90 & 45.00 & 52.70 & 56.00 & 3.34 \\
\hline $6 \mathrm{~N} 1.5$ & & 9.0 & 80 & 47.00 & 56.50 & 58.67 & 2.87 \\
\hline $6 \mathrm{~N} 3.0$ & & 18.0 & 100 & 45.00 & 54.50 & 56.50 & 2.55 \\
\hline
\end{tabular}

\subsection{Fresh properties of NS concrete}

Table (4) shows the results of slump test according to BS 1881-102. In general, all slump values are in the designed range of $80-100 \mathrm{~mm}$ for all investigated mixes. It is clear that, by increasing the amount of nano silica (NS), the required amount of superplasticizer increased to adjust the slump of mixture. These results are agreed with the results in $[1,3,19,20]$. According to these researches, the using of higher content of NS must be accompanied by adjustment of the water and superplasticizer dosage in the mix in order to ensure that specimens do not suffer excessive self-desiccation and cracking. The increase in the required water of standard consistency is attributed to the acceleration of the hydration process of cement phases under the effect of high fineness and surface energy of NS particles.

\subsection{Hardened properties of concrete 3.2.1 Ordinary concrete a) Compressive strength}

Figure (4) shows the effect of cement content $\left(300,400,500\right.$ and $\left.600 \mathrm{~kg} / \mathrm{m}^{3}\right)$ on the compressive strength $\left(f_{\text {cu }}\right)$ of concrete at 7, 28 and 56 days. In general, it is clear that $f_{\text {cu }}$ increases with increasing cement content at the different testing ages investigated.

Figure (5) shows the effect of testing age (7, 28, 56 days) on compressive strength of concrete made with different cement contents. It is clear that, compressive strength increases with increasing testing ages for all cement contents. The rate of increase in compressive strength is height from 7 to 28 days testing age. On increasing testing age from 28 to 56 days, a marginal increase in compressive strength was observed and this is dependent on the amount of cement content. The ratios between the compressive strengths at different testing age were calculated related to the strength at 28 days and the results are given in Table (5). It is clear that, the ratio $f_{\text {cu }} / f_{\text {c28 }}$ increases with increasing cement content. This reflect the high effect of increasing cement content on the early strength development of concrete. The relation between $f_{\text {cur }} / f_{\text {c28 }}$ and cement content is drawn in Figure (6) which reflect this behavior. The data in Figure (6) best fit the following equation between $f_{\mathrm{cu} 7} / f_{\mathrm{c} 28}$ and cement content $(\mathrm{CC})$

$$
f_{\text {cu7 }} / f_{\text {c28 }}=0.143(\mathrm{CC})^{0.281}
$$

The relation between $f_{\text {cu56 }}$ and $f_{\text {cu28 }}$ was also estimated as shown in Table (5). It is clear that $\boldsymbol{f}_{\text {cu56 }} / f_{\text {c28 }}$ decreases with increasing cement content which is opposite to the trend of $\boldsymbol{f}_{\text {cu56 }} / f_{\text {c28 }}$. The relation between $f_{\text {cu56 }} / f_{\text {c28 }}$ and cement content is drawn in Figure (7), which reflect this behavior. The data in Figure (7) best fit the following equation between $f_{\text {cusb }} / f_{\mathbf{c 2 8}}$ and CC :

$$
f_{\text {cu56 }} / f_{\mathrm{c} 28}=2.108(\mathrm{CC})^{-0.108} \quad(2)
$$




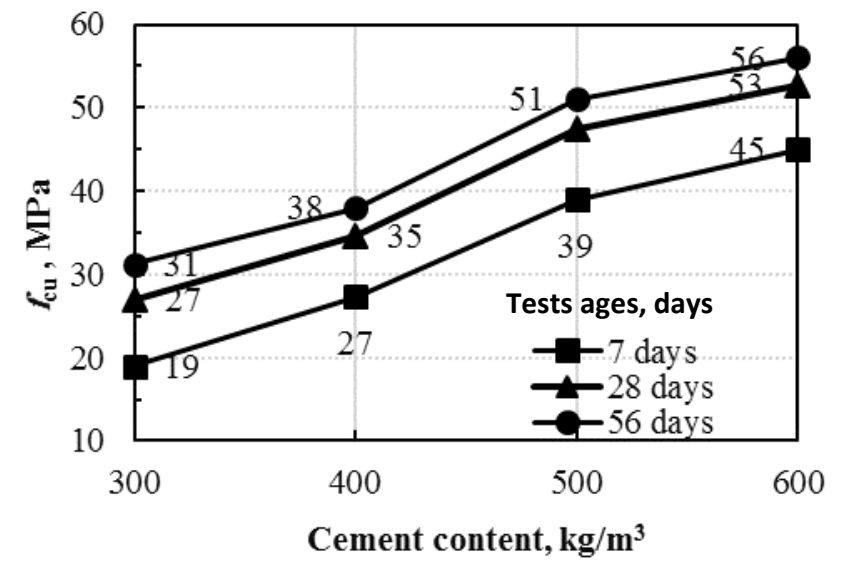

Figure (4): Effect of cement content on compressive strength of concrete at different testing ages.

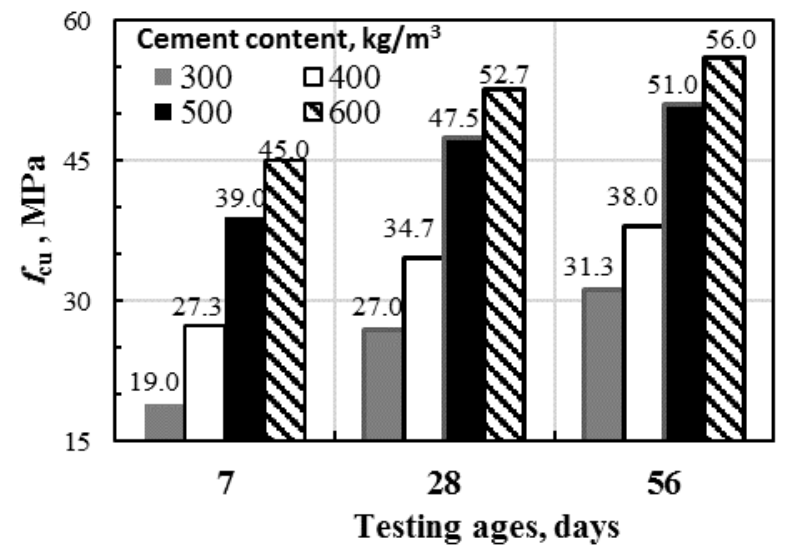

Figure (5): Effect of testing ages on compressive strength of concrete with different cement contents

Table (5): Compressive strength ratios of concrete at different testing ages.

\begin{tabular}{|c|c|c|}
\hline \hline Cement content, $\mathbf{k g} / \mathbf{m}^{3}$ & $\boldsymbol{f}_{\text {cu7 }} / \boldsymbol{f}_{\text {cu28 }}$ & $\boldsymbol{f}_{\text {cu56 }} / \boldsymbol{f}_{\text {cu28 }}$ \\
\hline \hline $\mathbf{3 0 0}$ & 0.70 & 1.14 \\
$\mathbf{4 0 0}$ & 0.79 & 1.10 \\
$\mathbf{5 0 0}$ & 0.83 & 1.07 \\
$\mathbf{6 0 0}$ & 0.85 & 1.06 \\
\hline \hline
\end{tabular}

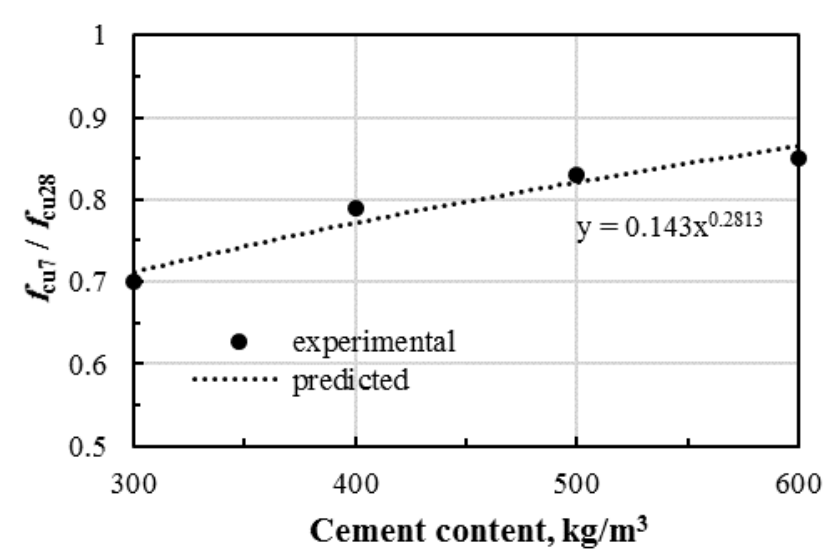

Figure (6): Effect of cement content on the compressive strength ratio, $f_{\mathrm{cu} 7} / f_{\mathrm{cu} 28}$.

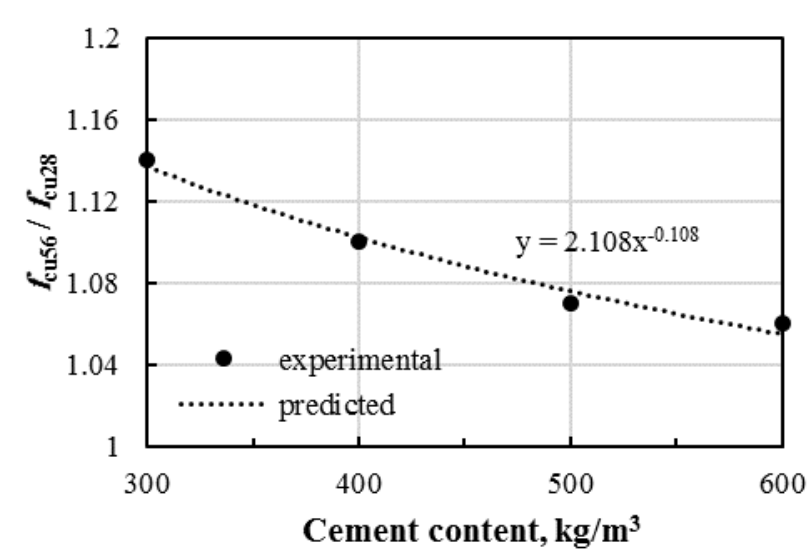

Figure (7): Effect of cement content on the compressive strength ratio, $f_{\text {cu56 }} / f_{\text {cu28. }}$.

\section{b) Water absorption at 28 days}

Figure (8) shows the effect of cement content $\left(300,400,500\right.$ and $\left.600 \mathrm{~kg} / \mathrm{m}^{3}\right)$ on WA\% of concrete without NS after 28 days. It is clear that with increasing cement content, WA\% decreases with a decreasing rate. Using $400 \mathrm{~kg} / \mathrm{m}^{3}$ cement content in concrete decreases the WA $\%$ by about $24.8 \%$ compared to concrete containing $300 \mathrm{~kg} / \mathrm{m}^{3}$ cement content. By increasing $\mathrm{CC}$ to $500 \mathrm{~kg} / \mathrm{m}^{3}$, WA \% decreases by a ratio of about $23.6 \%$ compared to $400 \mathrm{~kg} / \mathrm{m}^{3}$ cement content. Rising CC from 500 to $600 \mathrm{~kg} / \mathrm{m}^{3}$ leading to decreasing WA\% by about $6.4 \%$ compared to concrete containing $500 \mathrm{~kg} / \mathrm{m}^{3}$. The data in Figure (8) best fit the following relation between $\mathrm{WA} \%$ and $\mathrm{CC}$ at 28 days.

$$
\text { WA \% }=1270.5(C \mathrm{C})^{-0.939}
$$




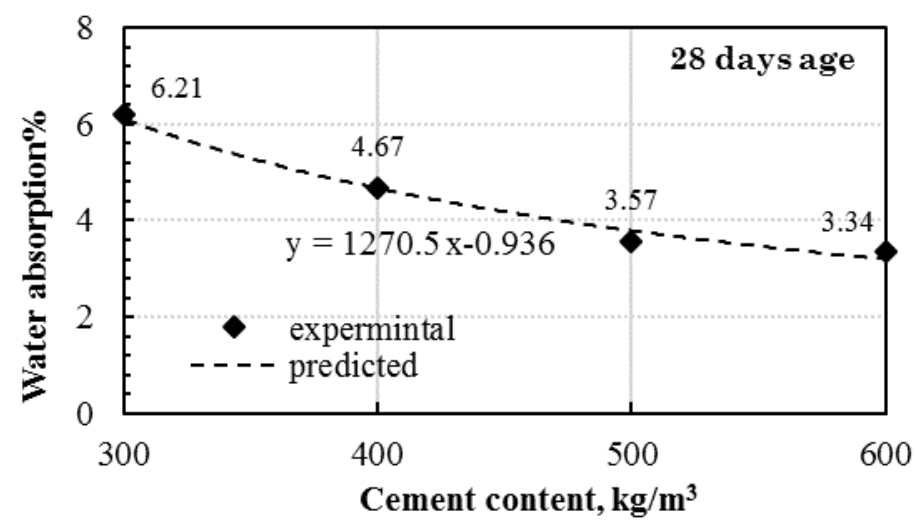

Figure (8): Effect of cement contents on WA\% of concrete.

\subsubsection{Nano Silica Concrete}

\section{a) Compressive strength}

Figures (9) shows the effect of NS by the percentages of $1.5 \%$ and $3 \%$ of $\mathrm{CC}$ on the compressive strength of concrete made with different cement contents $\left(300,400,500,600 \mathrm{~kg} / \mathrm{m}^{3}\right)$ at 7 days. The results in the Figures clearly indicate that replacing $1.5 \%$ of cement by NS enhanced $f_{\text {cu7 }}$ of concrete at different cement contents. On increasing this ratio to $3 \%, f_{\text {cu } 7}$ decreased compared to that at $1.5 \% \mathrm{NS}$ but the compressive strength is still higher than that of the concrete mix without NS. Since the spherical particles of NS have an extremely large surface area compared to cement particle, the NS reacts very rapidly with $\mathrm{CH}$ to form calcium silicate in an alkaline environment. For this reason, the enhancement in $f_{\text {cu }}$ due to using NS becomes more obvious in the early age $[8,12,19-21]$.

The ratios of the compressive strength of concrete mix containing $1.5 \% \mathrm{NS}\left(f_{\text {cu1.5 }}\right)$ and that containing $3 \%$ NS $\left(f_{\text {cu3.0 }}\right)$ to that of the concrete mix without NS at 7 days $\left(f_{\text {cu } 0}\right)$ were calculated at different cement contents as given in Table (6). The data in Table (6) was represented in Figures (10) and (11). It is clear that, $\boldsymbol{f}_{\text {cu1.5 }} / f_{\text {cu0 }}$ and $\boldsymbol{f}_{\text {cu3.o }} / f_{\text {cu0 }}$ decrease with increasing cement content. The rate of decrement in both ratios is small when cement content increases from 300 to $400 \mathrm{~kg} / \mathrm{m}^{3}$ and after that, this rate of decrement sharply increased. This means that, the role of NS in enhancing $f_{\text {cu }}$ is more pronounced at low levels of cement contents.

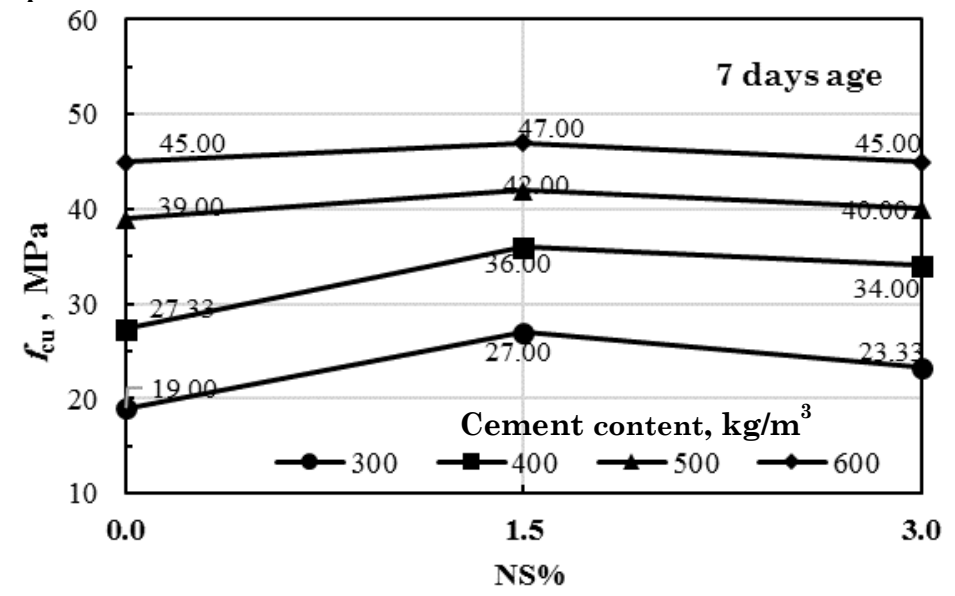

Figure (9): Effect of cement contents on the compressive strength of concrete containing NS 
Table (6): Enhancement ratios in $f_{\text {cu }}$ as a result of NS addition at different $\mathrm{CC}$ at 7 days

\begin{tabular}{|ccc|}
\hline \hline $\begin{array}{c}\text { Cement content, } \\
\mathbf{k g} / \mathbf{m}^{\mathbf{3}}\end{array}$ & $\boldsymbol{f}_{\text {cu1.5 }} / \boldsymbol{f}_{\text {cu0 }} \%$ & $\boldsymbol{f}_{\text {cu3.0 }} / \boldsymbol{f}_{\text {cu0 }} \%$ \\
\hline $\mathbf{3 0 0}$ & 142.11 & 122.79 \\
$\mathbf{4 0 0}$ & 131.72 & 117.1 \\
$\mathbf{5 0 0}$ & 107.69 & 102.56 \\
$\mathbf{6 0 0}$ & 104.44 & 100.22 \\
\hline
\end{tabular}

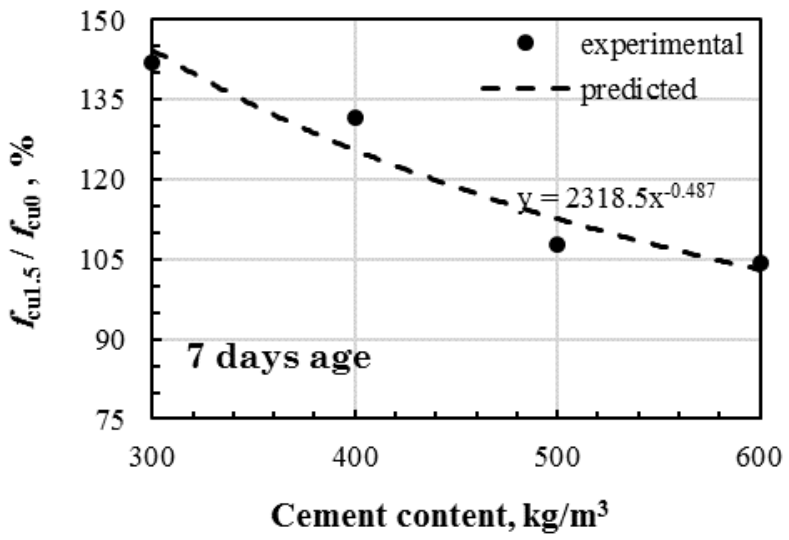

Figure (10): Effect of cement content on compressive strength ratio of concrete containing $1.5 \% \mathrm{NS}$

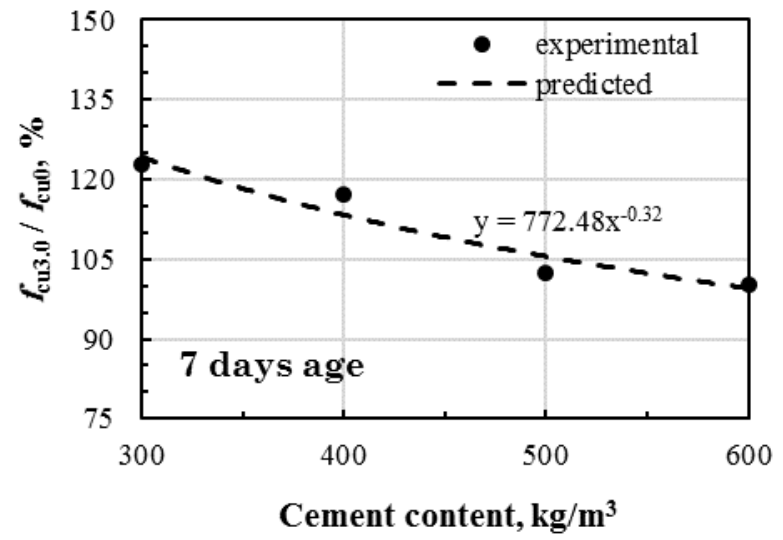

Figure (11): Effect of cement content on compressiv strength ratio of concrete containing $3.0 \% \mathrm{NS}$

The data in Figure (10) best fit the following relation between $f_{\text {cu1.5 }} / f_{\text {cu0 }} \%$ and CC at 7 days.

$$
f_{\text {cu1.5 }} / f_{\text {cu0 }} \%=2318.5(\mathrm{CC})^{-0.487}
$$

The data in Figure (11) also best fit the following relation between $f_{\text {cu3.o }} / f_{\text {cu0 }} \%$ and CC at 7 days.

$$
f_{\text {cu3.0 }} / f_{\text {cu0 }} \%=772.48(\mathrm{CC})^{-0.320}
$$

Figure (12) shows the effect of NS by the percentages of $1.5 \%$ and $3 \%$ of CC on the compressive strength of concrete made with different cement contents $\left(300,400,500,600 \mathrm{~kg} / \mathrm{m}^{3}\right)$ at 28 days. The results in the Figures clearly indicate that replacement of cement by $1.5 \%$ NS enhanced $f_{\text {cu } 28}$ of concrete at the different cement contents. On increasing this ratio to $3 \%, f_{\text {cu2 } 28}$ decreased compared to that at $1.5 \%$ NS but the compressive strength is still higher than that of the concrete mix without NS. This increase in $f_{\text {cu2 } 2}$ may be because silica is the most important cement pozzolanic composition that reacts to the calcium hydroxide resulted from cement hydration and produces $\mathrm{H}-\mathrm{C}-\mathrm{S}$ gel, which is the main factor of concrete strength. In addition, the speed of this pozzolanic reaction depends on the reaction accessible surface. Since NS has a very high specific surface, it is able to do the pozzolanic reaction very well [10, 22-24]. As shown in Figure (12), the maximum compressive strength is observed for concrete with $1.5 \% \mathrm{NS}$. On increasing NS to $3.0 \%, f_{\text {cu28 }}$ decreased.

The decrease in $f_{\text {cu }}$ with increasing NS content was reported by Li et al. [25]. They explained that "After hydration begins, hydrate products diffuse and envelop nano-particles as kernel. If the content of nano-particles and the distance between them are appropriate, the crystallization will be controlled to be a suitable state through restricting the growth of $\mathrm{Ca}(\mathrm{OH})_{2}$ crystal by nano- 
particles. This makes the cement matrix more homogeneous and compact. With increasing content of nano-particles, the distance between nanoparticles decreases, $\mathrm{Ca}(\mathrm{OH})_{2}$ crystal cannot grow up enough, which results in a decrease in the ratio of crystal to C-S-H gel and the microstructure of cement matrix becomes loose'. When the percentage of NS is large, the weak zone in concrete increases which results in a decrease in concrete strength. This decrease in $f_{\text {cu }}$ may be due to the agglomeration and defects generated in dispersion of NS particles $[4,26]$.

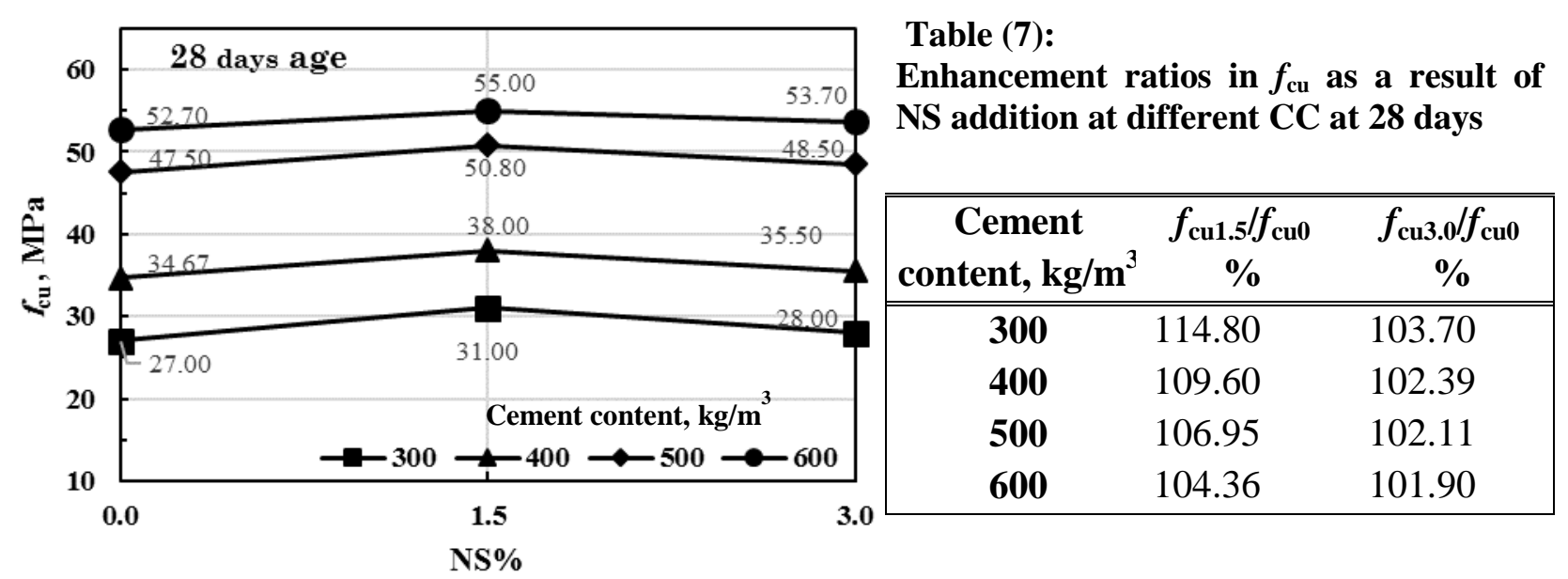

Figure (12): Effect of cement contents on compressive strength of concrete containing NS.

The ratios of the compressive strength of concrete mix containing $1.5 \% \mathrm{NS}\left(f_{\text {cu1.5 }}\right)$ and that containing $3 \% \mathrm{NS}\left(f_{\text {cu3.0 }}\right)$ to that of the concrete mix without NS at $\left(f_{\text {cu } 0}\right) 28$ days were estimated at different cement contents as illustrated in Table (7). The data in Table (7) was represented in Figures (13) and (14). It is clear that, $f_{\text {cu1.5 }} / f_{\text {cu0 }}$ and $f_{\text {cu3.0 }} / f_{\text {cu0 }}$ decrease with increasing cement content. These ratios are less than those recorded at 7 days at both NS\% of $1.5 \%$ and $3 \%$.

The data in Figure (13) best fit the following relation between $f_{\text {cui. }} / f_{\text {cu0 }} \%$ and $\mathrm{CC}$ at 28 days.

$$
f_{\text {cu1.5 }} / f_{\text {cu0 }} \%=248.29(\mathrm{CC})^{-0.136}
$$

The data in Figure (14) best fit the following relation between $f_{\text {cu3.o }} / f_{\text {cu0 }} \%$ and $\mathrm{CC}$ at 28 days.

$$
f_{\text {cu3.0 }} / f_{\text {cu0 }} \%=119.23(\mathrm{CC})^{-0.025}
$$

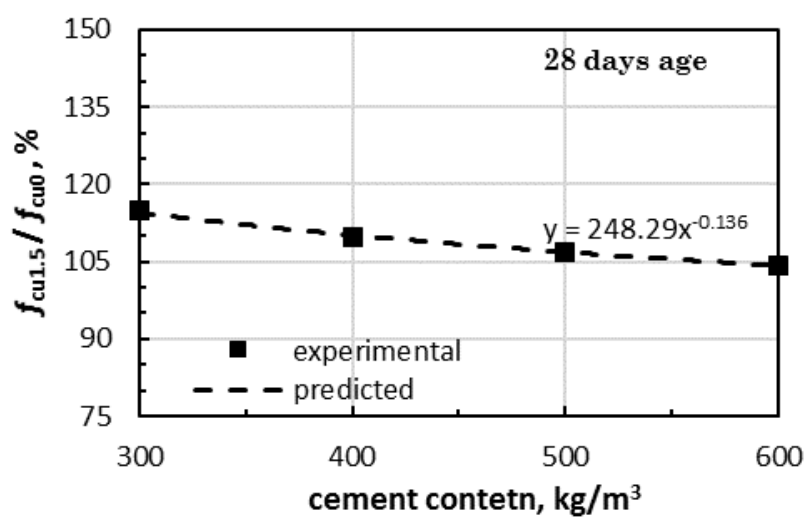

Figure (13): Effect of cement content on compressive

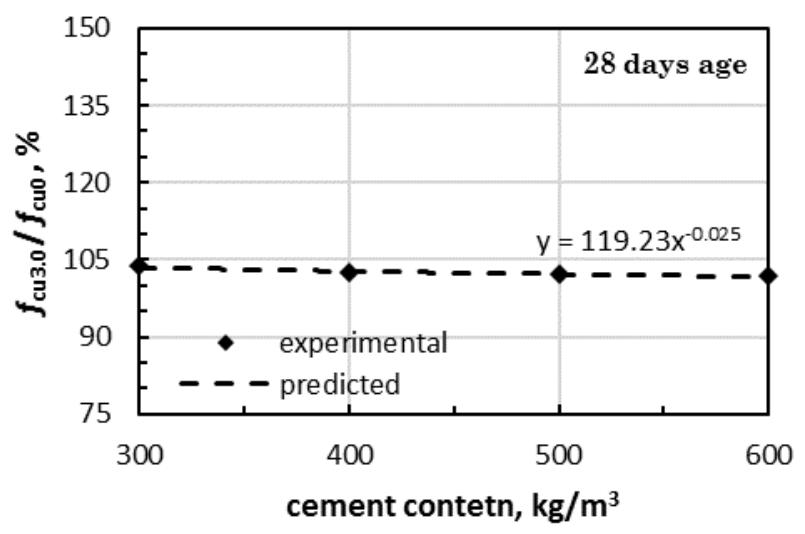

Figure (14): Effect of cement content on compressive 
strength ratio of concrete containing $1.5 \% \mathrm{NS}$

strength ratio of concrete containing $3.0 \% \mathrm{NS}$ Figure (15) shows the effect of NS by the percentages of $1.5 \mathrm{wt} . \%$ and $3 \mathrm{wt} . \%$ of cement content on the compressive strength of concrete made with different cement contents $(300,400,500,600$ $\mathrm{kg} / \mathrm{m}^{3}$ ) at 56 days. The results in the Figures clearly indicate that replacing of cement by $1.5 \% \mathrm{NS}$ enhanced $f_{\text {cu56 }}$ of concrete at the different cement contents. On increasing this ratio to $3 \%, f_{\text {cu56 }}$ decreased compared to that at $1.5 \%$ NS but the compressive strength still higher than that of the concrete mix without NS. Based on the available data, the positive action of the nanoparticles can be occurring if the amount of nanoparticles and their spacing is suitable formation process of crystals in the transition area, as a result, strength improvement. As mentioned earlier, NS having high special surface are likely to stick together, through a physical reaction, and form unstable balls and that is explaining the decrease in strength with increasing NS amount to 3\%. This result agrees with $[6,27]$. This trend is observable at all ages.

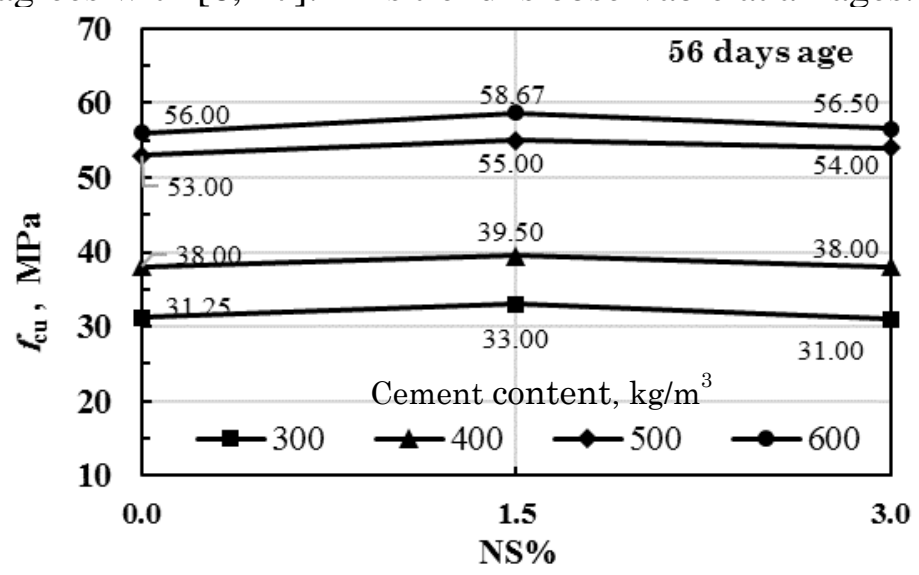

Table (8):

Enhancement ratios in $f_{\text {cu }}$ as a result of NS addition at different $\mathrm{CC}$ at 56 days

\begin{tabular}{|ccc|}
\hline $\begin{array}{c}\text { Cement content, } \\
\mathbf{k g} / \mathbf{m}^{\mathbf{3}}\end{array}$ & $\boldsymbol{f}_{\text {cu1.5 }} / f_{\text {cu0 }} \%$ & $\boldsymbol{f}_{\text {cu3.o }} / f_{\text {cu0 }} \%$ \\
\hline $\mathbf{3 0 0}$ & 106.45 & 103.23 \\
$\mathbf{4 0 0}$ & 105.26 & 102.11 \\
$\mathbf{5 0 0}$ & 104.90 & 100.98 \\
$\mathbf{6 0 0}$ & 104.77 & 100.89 \\
\hline
\end{tabular}

Figure (15): Effect of cement contents on compressive strength of concrete containing NS\%

The ratios of the compressive strength of concrete mix containing $1.5 \% \mathrm{NS}\left(f_{\text {cu1.5 }}\right)$ and that containing $3 \%$ NS $\left(f_{\text {cu } 3.0}\right)$ to that of the concrete mix without NS at 56 days $\left(f_{\text {cu0 }}\right)$ were estimated at different cement contents as illustrated in Table (8). The data in Table (8) was represented in Figures (16) and (17). It is clear that, $\boldsymbol{f}_{\text {cu1.5 }} / f_{\text {cu0 }}$ and $\boldsymbol{f}_{\text {cu3.0 }} / f_{\text {cu0 }}$ decreased with increasing cement content. Those ratios are less than those recorded at 7 and 28 days at both NS\% of $1.5 \%$ and $3.0 \%$. A marginal effect of cement contents on $f_{\text {cu1.5 }} / f_{\text {cu0 }}$ and $f_{\text {cu3.0 }} / f_{\text {cu0 }}$ was observed. So, we can conclude that, the major effect of cement content on the compressive strength of concrete mix were found at early age (7 days).

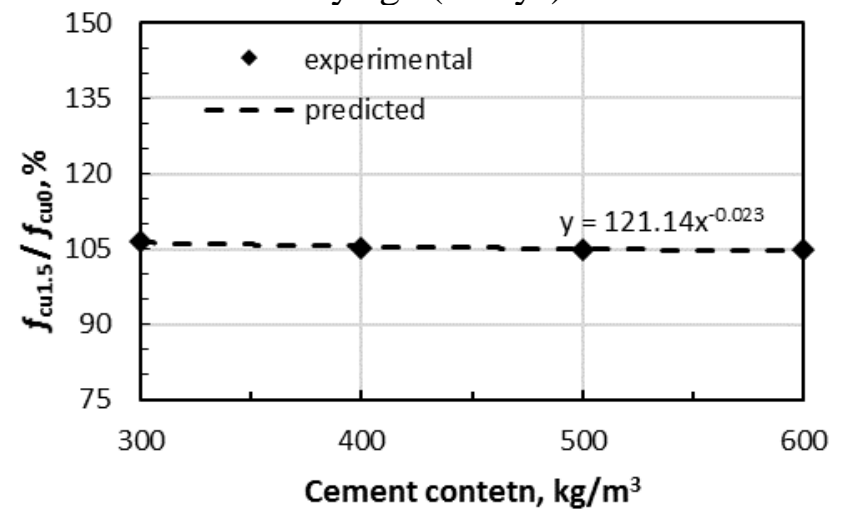

Figure (16): Effect of cement content on compressive strength ratio of concrete containing $1.5 \% \mathrm{NS}$

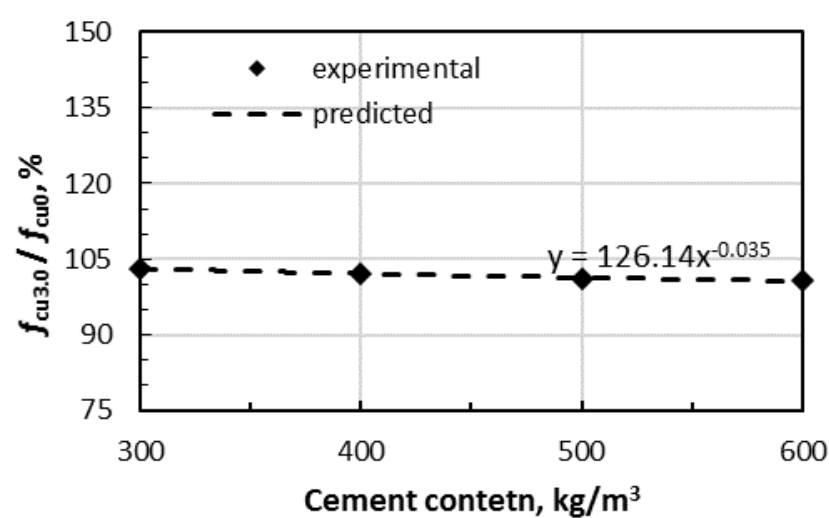

Figure (17): Effect of cement content on compressive strength ratio of concrete containing $3.0 \%$ NS

The data in Figure (16) best fit the following relation between $f_{\text {cu1.5 }} / f_{\text {cu0 }} \%$ and CC at 56 days. 


$$
f_{\text {cu1.5 }} / f_{\text {cu0 }} \%=121.14(\mathrm{CC})^{-0.023}
$$

The data in Figure (17) also best fit the following relation between $f_{\text {cu3.0 }} / f_{\text {cuo }} \%$ and CC at 56 days.

\section{b) Water absorption at 28 days}

$$
f_{\text {cu3.0 }} / f_{\text {cu0 }} \%=126.14(\mathrm{CC})^{-0.035}
$$

Figure (18) shows the effect of NS by two amount (1.5\% and 3.0\% of cementitious material) on WA\% of concrete made with different cement contents at 28 days. In Figure (18), using NS in general improved concrete resistance for WA. This may be due to the properties of concrete which improved by the use of NS, since NS particles fill the voids between cement grains and also consume a part of $\mathrm{CH}$ which results in additional formation of $\mathrm{C}-\mathrm{S}-\mathrm{H}$ and more improvement of interface structure. Therefore, the permeability of the concrete would decreases by nano particles filling the pores at nano level [11, 25, 28]. In Figure (19), it is clear that, water absorption reduction increases by increasing NS to $3 \%$ in concrete. This may be because NS can acts as a nucleus to tightly bond with $\mathrm{C}-\mathrm{S}-\mathrm{H}$ gel particles. Thus, the integration and stability of the hydration product structure are improved, and long-term durability of concrete are expected to be increased [10]. These results agree with Beigi et al. [26]. They explained that with increasing NS up to $4 \%$, the total specific pore volumes of concretes are decreased, and the most probable pore diameters of concretes shift to smaller pores. According to the results found in [10, $23,29]$, with increasing content of NS, the improvement in the pore structure of concrete is apparent. The distance between nanoparticles decreases with increasing content of nanoparticles, and $\mathrm{Ca}(\mathrm{OH})_{2}$ crystal cannot grow up enough due to limited space and the crystal quantity is decreased which leads to the ratio of crystal to strengthening gel small and the shrinkage of cement matrix is decreased.

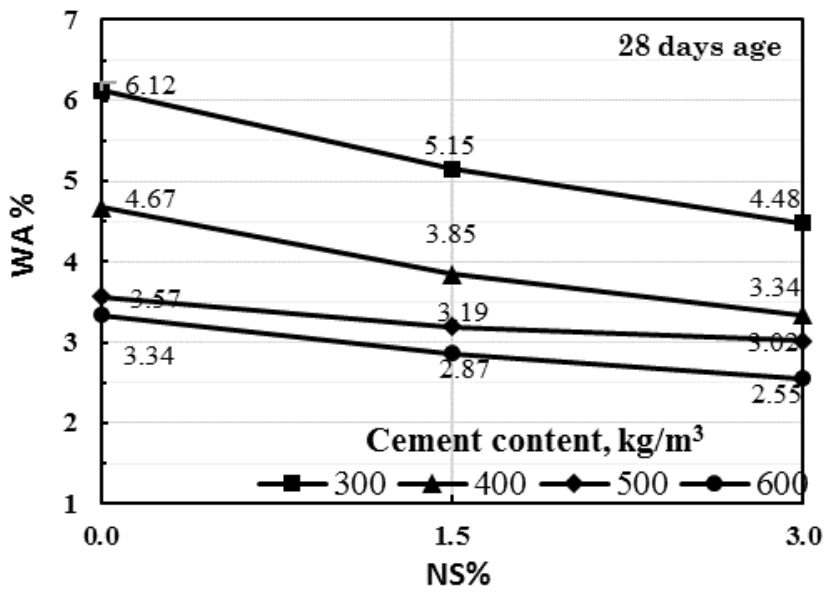

Figure (18): Effect of NS\% on WA\% of concretes at different cement contents.

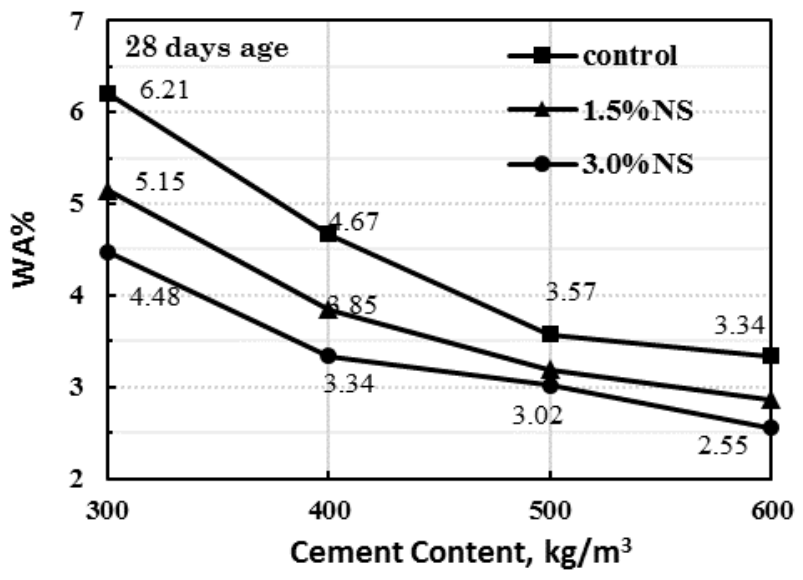

Figure (19): Effect of cement contents on WA\% of concretes containing NS\%

The data in Figure (20) best fit following relation between WA\% after using $1.5 \%$ NS $\left(\mathrm{WA} \%{ }_{\mathrm{NS} 1.5}\right)$ and $\mathrm{CC}$ at 28 days.

$$
\text { WA } \% \text { Ns1. } 5=654.12(C C)^{-0.853}
$$

The data in Figure (21) also best fit following relation between WA\% after using 3.0\% NS (WA\% $\%_{\text {NS3.0) }}$ and $\mathrm{CC}$ at 28 days.

$$
\text { WA } \% \text { NS3.0 }=382.24(C C)^{-0.783}
$$




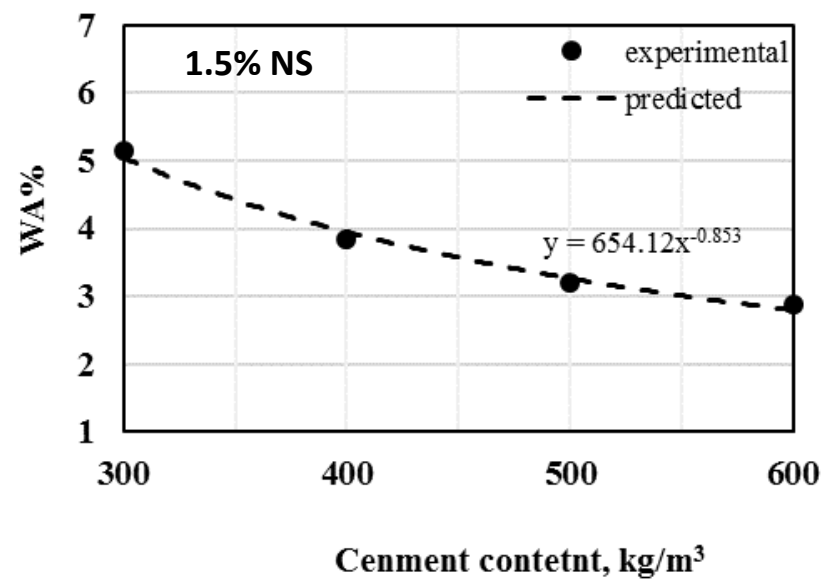

Figure (20): Effect of $1.5 \%$ NS on water absorption \% of concrete

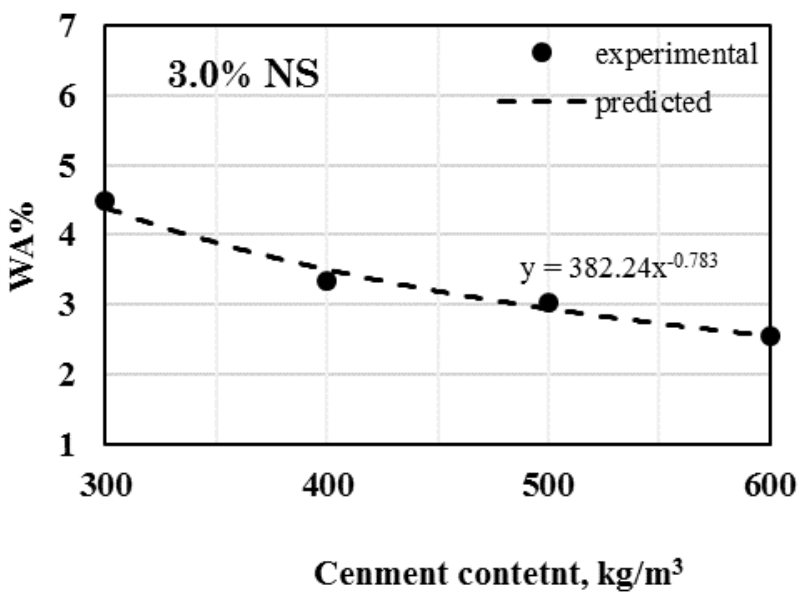

Figure (21): Effect of $3.0 \%$ NS on water absorption \% of concrete

\section{CONCLUSIONS}

The results of the present experimental work support the following conclusions:

1. The ratios of concrete compressive strength at 7 and 56 days to that at 28 days $\left(f_{\text {cu }} / f_{\text {cu2 }} 8\right.$ and $\left.f_{\text {cu5 } 6} f_{\text {cu2 } 8}\right)$ for different cement contents was found and correlated. The ratio $f_{\text {cu }} / f_{\text {cu2 }} 8$ was found to increase with increasing cement content while $f_{\text {cus }} f f_{\text {cu2 }}$ showed an opposite trend.

2. The addition of NS significantly increased the 7-day, 28-day and 56-day cube strengths. The replacement of cement by $1.5 \%$ NS enhanced compressive strength of concrete at different cement contents to maximum. On increasing this ratio to $3 \%$, compressive strength decreased compared to that at $1.5 \%$ NS but the still higher than that of the concrete mix without NS.

3. At early age, relations $f_{\text {cul.5. }} / f_{\text {cu } 0} \%$ and $f_{\text {cu3.o }} / f_{\text {cu } 0} \%$ decreased with increasing cement content. The rate of decrement in both ratios is small when cement content increases from 300 to $400 \mathrm{~kg} / \mathrm{m}^{3}$ and after that, this rate of decrement is sharply increased. This means that, the role of NS in enhancing compressive strength is more pronounced at low levels of cement contents.

4. After 56 days, relations $f_{\text {cu } 1.5} / f_{\text {cu } 0} \%$ and $f_{\text {cu3.o }} / f_{\text {cu } 0} \%$ are less than those recorded at 7 and 28 days at both. A marginal effect of cement contents on $f_{\text {cu1.5 }} / f_{\text {cu } 0} \%$ and $f_{\text {cuz.o }} / f_{\text {cu } 0} \%$ is observed. So, we can conclude that, the major effect of cement content on the compressive strength of concrete mix was observed at early age (7 days).

5. It was found that with increasing cement content, water absorption decreased with a decreasing rate.

6. Using NS in concrete by $1.5 \%$ and $3.0 \%$ enhanced concrete resistance for water absorption.

\section{REFERENCES}

[1]. Quercia, G., Hüsken, G. and Brouwers, H.J.H., "Water demand of amorphous nano silica and its impact on the workability of cement paste". Cement and Concrete Research, 42(2), pp.344-357. (2012).

[2]. Li, H., Xiao, H.G., Yuan, J. and Ou, J., "Microstructure of cement mortar with nanoparticles". Composites Part B: Engineering, 35(2), pp.185-189. (2004).

[3]. Björnström, J., Martinelli, A., Matic, A., Börjesson, L. and Panas, I., "Accelerating effects of colloidal nano-silica for beneficial calcium-silicate-hydrate formation in cement." Chemical Physics Letters, 392(1), pp.242-248. (2004). 
[4]. Senff, L., Labrincha, J.A., Ferreira, V.M., Hotza, D. and Repette, W.L., "Effect of nanosilica on rheology and fresh properties of cement pastes and mortars." Construction and Building Materials, 23(7), pp.2487-2491. (2009).

[5]. Qing, Y.E., Zenan, Z., Li, S. and Rongshen, C., "A comparative study on the pozzolanic activity between nano-SiO2 and silica fume." Journal of Wuhan University of Technology--Materials Science Edition, 21(3), pp.153-157. (2006).

[6]. Givi, A.N., Rashid, S.A., Aziz, F.N.A. and Salleh, M.A.M., "Experimental investigation of the size effects of $\mathrm{SiO} 2$ nano-particles on the mechanical properties of binary blended concrete." Composites Part B: Engineering, 41(8), pp.673-677. (2010).

[7]. Givi, A.N., Rashid, S.A., "A12O3 nanoparticles in concrete and different curing media." Energy and Buildings, 43(6), pp.1480-1488. (2011).

[8]. Nili, M. and Ehsani, A., "Investigating the effect of the cement paste and transition zone on strength development of concrete containing nanosilica and silica fume." Materials \& Design, 75, pp.174-183. (2015).

[9]. Amin, M. and Abu el-Hassan, K., "Effect of using different types of nano materials on mechanical properties of high strength concrete." Construction and Building Materials, 80, pp.116-124. (2015).

[10]. Ji, T., "Preliminary study on the water permeability and microstructure of concrete incorporating nano-SiO2." Cement and Concrete Research, 35(10), pp.1943-1947. (2005).

[11]. Shebl, S.S., Allie, L., Morsy, M.S. and Aglan, H.A., "Mechanical behavior of activated nano silicate filled cement binders." Journal of materials science, 44(6), pp.1600-1606. (2009).

[12]. Jalal, M., Mansouri, E., Sharifipour, M. and Pouladkhan, A.R., "Mechanical, rheological, durability and microstructural properties of high performance self-compacting concrete containing SiO2 micro and nanoparticles.” Materials \& Design, 34, pp.389-400. (2012).

[13]. Behfarnia, K. and Salemi, N., "The effects of nano-silica and nano-alumina on frost resistance of normal concrete." Construction and Building Materials, 48, pp.580-584. (2013).

[14]. EN, B., “197-1: 2011”. Cement, Composition, Specifications and Conformity Criteria for Common Cements. London, England: British Standard Institution (BSI). (2011).

[15]. Specifications, E.S., "ES 4756-1/2005." Ordinary Portland Cement CEMI (42.5 N), Egypt. (2005).

[16]. Standard, B., "Part-102 (1983) Testing Concrete Method for Determination of Slump", London. British Standard Institution. (1881).

[17]. Standard, B., "Part 116: 1983." Method for Determination of Compressive of Concrete Cube. (1881).

[18]. ASTM, C., 642, "Standard test method for density, absorption, and voids in hardened concrete." Annual book of ASTM standards, 4. (2006).

[19]. Qing, Y., Zenan, Z., Deyu, K. and Rongshen, C., "Influence of nano-SiO2 addition on properties of hardened cement paste as compared with silica fume." Construction and Building Materials, 21(3), pp.539-545. (2007).

[20]. Jo, B.W., Kim, C.H. and Lim, J.H., "Investigations on the development of powder concrete with nano-SiO2 particles." KSCE Journal of Civil Engineering, 11(1), pp.37-42. (2007).

[21]. Du, H., Du, S. and Liu, X., "Effect of nano-silica on the mechanical and transport properties of lightweight concrete." Construction and Building Materials, 82, pp.114-122. (2015).

[22]. Sobolev, K. and Gutiérrez, M.F., "How nanotechnology can change the concrete world." American Ceramic Society Bulletin, 84(10), p.14. (2005).

[23]. Choolaei, M., Rashidi, A.M., Ardjmand, M., Yadegari, A. and Soltanian, H., "The effect of nanosilica on the physical properties of oil well cement." Materials Science and Engineering: A, 538, pp.288-294. (2012). 
[24]. Gaitero, J.J., Campillo, I. and Guerrero, A., "Reduction of the calcium leaching rate of cement paste by addition of silica nanoparticles." Cement and Concrete Research, 38(8), pp.1112-1118. (2008).

[25]. Li, H., Zhang, M.H. and Ou, J.P., "Flexural fatigue performance of concrete containing nano-particles for pavement." International Journal of fatigue, 29(7), pp.1292-1301. (2007).

[26]. Beigi, M.H., Berenjian, J., Omran, O.L., Nik, A.S. and Nikbin, I.M., "An experimental survey on combined effects of fibers and nanosilica on the mechanical, rheological, and durability properties of self-compacting concrete". Materials \& Design, 50, pp.10191029. (2013).

[27]. Li, H., Zhang, M.H. and Ou, J.P., "Abrasion resistance of concrete containing nanoparticles for pavement." Wear, 260(11), pp.1262-1266. (2006).

[28]. Mohseni, E., Miyandehi, B.M., Yang, J. and Yazdi, M.A., "Single and combined effects of nano-SiO2, nano-A12O3 and nano-TiO2 on the mechanical, rheological and durability properties of self-compacting mortar containing fly ash." Construction and Building Materials, 84, pp.331-340. (2015).

[29]. Hasehmpour, H., Atashgah, K.M. and Rezaei, M.K., "An Investigation into the Role of Nano-Silica in Improving Strength of Lightweight Concrete." European Online Journal of Natural and Social Sciences, 3(4), p.1058. (2014) 